\title{
The Rise and Fall of CSR in Italian Local Government
}

\author{
Luca Bisio*
}

\begin{abstract}
CSR is an essential intangible business asset increasingly understood as a critical success factor in global markets. A new connotation of corporate responsibility, combined with a modern approach to CSR interpreted in a competitive key, can bring together economic and socio-environmental performance needs by providing adequate responses to a wide range of stakeholders. This, however, requires guaranteeing sustainability from an economic point of view as well as credibility in terms of the messages conveyed with the related communication tools. The Italian public sector has attempted to incorporate the managerial approach developed in the private sector, yet after a period of great attention to this issue, a gradual decline has manifested in the instruments supporting social responsibility and the importance they play in the internal programming, reporting, and communications cycle. About 20 years after the introduction of the social report, it is possible to affirm that this tool has not been rooted in the practices of Italian public administrations.
\end{abstract}

Keyword: Corporate Social Responsibility; Local government; Global Markets; CSR Guidelines

\section{CSR and Global Markets}

More socially developed countries are increasingly characterized by over-supply markets, forcing firms to compete in a spiral of neoliberalism with the exasperated search for opportunities for vital market spaces without limitations (market-space competition), and with increasingly constricted action-reaction times (time-based competition).

Due to the competitive dynamics of firms, over-supply leads to overestimating the importance of very short-term results, focusing attention on the timing and on the levels of return of productive factors, and eliminating the costs of local social development.

For this reason, globalization has led to increasing awareness of social and environmental issues, and more generally, the sustainable growth of organizations.

For a long time, corporate governance focused solely on meeting shareholder expectations in terms of profit maximization. The capitalism logic, understood in the conventional sense, was substantially reticent in assigning value to the dissipation of natural resources and to the social system in which it was rooted (Hawken, A. et al., 1999).

* Assistant Professor of Management, University of Milan-Bicocca (luca.bisio@unimib.it) 
In this sense, corporate management focused on a single objective: "make money for stakeholders", in evidence of a certain moral myopia (Freeman, R.E. et al., 2004).

The importance of the CSR concept has been much underestimated, and The Economist prior to 2007 (completely espousing Milton Freeman's vision and summarizing the contributions of a significant part of the scholarship) reiterated that, "there is one and only one social responsibility of business - to use it resources and engage in activities designed to increase its profits so long as it stays within the rules of the game, which is to say, engages in open and free competition without deception or fraud" (The Economist Supplement, 2005).

Only three years later, and in the midst of the crisis, while maintaining a critical attitude towards CSR, the Economist nevertheless admitted the significant diffusion of the phenomenon within global companies, also as a result of the increasing pressure exerted by a plurality of stakeholder categories (The Economist Supplement, 2008).

In fact, "Several socio-economic mutations and technological breakthrough innovations are currently modifying the competitive environment and the functioning of today's economies" (Lambin, J.J., 2014).

Firms are exposed to large-scale socio-environmental tensions, which can only be reconciled with modern corporate social responsibility that is able to express a global firm's corporate responsibility with a view to sustainable growth.

"The debate over corporate conduct in a context of sustainable development has taken on new importance in recent times. It is an area that generates great interest among public opinion; a public increasingly well-informed and attentive to the ethical aspects of the company and prepared to recognise the lead played by those companies with responsible and socially oriented behaviour (Brondoni S.M., 2003)."

As a result of more informed and attentive stakeholders concerned with social and environmental issues, beyond the economic, firms with greater awareness recognize that an orientation towards shareholders alone is no longer sufficient. The stakeholder oriented logic is not only more impartial in considering all stakeholders, but is also able to provide greater value to shareholders themselves (Freeman, R.E. et al., 2004).

As a result, stakeholder relations have been re-evaluated as an essential condition for long-term success (Salvioni, D.M., 2003).

In particular, according to Porter (Porter, M.E. \& Kramer M.R., 2007), analysing the four constituent elements of the competitive environment, firms can identify within each the overlap between economic and social value, and thus improve their economic and social performance in the medium term (Porter, M.E., Kramer, M.R., 2007).

More precisely, CSR actions can have a positive impact on:

- the presence of an expert workforce, qualified scientific institutions, and adequate infrastructures (impact on inputs);

- the volume and qualitative dimension of demand (impact on demand);

- transparency and the degree of cooperation of the competitive framework of reference (impact on the strategic and competitive context); 
- the degree of development of agreements between firms and the soundness of support organisations (impact on related and support sectors).

Clearly emerging from these premises it that CSR has in recent years generated "great interest among public opinion; a public increasingly well-informed and attentive to the ethical aspects of the company and prepared to recognise the lead played by those companies with responsible and socially oriented behaviour" (Brondoni, 2003).

\section{Different Approaches to CSR}

In global markets, corporate responsibility is aimed at pursuing (partial and total) business results characterized by high levels of profitability and efficiency, but prioritising the sustainability of development. In global companies, corporate social responsibility is aimed at managing the stakeholder system (i.e., the set of organizational, social, and environmental stakeholders).

The purpose of sustainable development is therefore expressed as the pursuit of a coherent and achievable balance between economic growth, environmental protection, and social justice. These constitute the triple bottom line expressed in:

- generating profit, as a necessary but insufficient condition for economic survival (economic result);

- limiting the environmental impact of the firm's decisions (environmental result);

- responding to the needs of its stakeholders (social result).

This threefold distinction of results requires firms to be able to report to a large group of actors. In this sense, the OECD definition defines governance as a set of relationships between the firm and its internal and external stakeholders.

Starting from these premises and analysing business behaviours, CSR actions can be interpreted according to at least two antithetical approaches:

- CSR as business philanthropy;

- CSR as a source of competitive advantage.

The first approach is characterized by a strong promotional emphasis. The firm uses CSR to protect its corporate identity from potential accusations of illicit behaviour (consider firms belonging to sectors strictly linked to the theme of environmental impact). In this case, CSR assumes the connotation of an advertising program or institutional propaganda in pursuit of objectives aiming to redevelop their image (Brondoni S.M., 2003) for firms that are well aware that public opinion positively judges those organizations engaged in social activities (Ricotti, P., 2003).

The second approach is instead consistent with the view of Porter and Kramer (2007) who identify CSR as a source of opportunity, innovation, and competitive advantage (Porter, M.E., Kramer, M.R., 2007).

In this case, CSR becomes a distinctive corporate factor in addressing the firm's audience. As such, organizations increasingly endow themselves with specific codes of conduct to respond to emerging issues on a global scale and provide a document aimed at defining a series of rules and codes of conduct, practices, and relationships, values and responsibilities towards stakeholders (Arrigo, E., 2012).

Faced with pro-active and informed stakeholders, CSR can therefore become a source of sustainable competitive advantage only if appropriately channelled. 
From this point of view, the correctness of information transmitted can be understood in at least three perspectives: effective, innovative, and economically sustainable communication through the use of digital tools enabling (Salvioni, D.M., Bosetti, L., 2014):

- overcoming historical information limits, ensuring greater timeliness;

- reducing costs related to the preparation and distribution of information;

- overcoming physical barriers linked to space;

- limiting information asymmetry between the firm and its customers.

These elements are not easy to manage. Although the monetary costs of digital communications are relatively lower, the non-monetary costs, in terms of time and resources dedicated, can be significantly higher.

Furthermore, stakeholders should not be considered as passive recipients of said communication but as active interlocutors of the governance relationship with the firm. In confirmation, to note is the strong push by various global organizations to strengthen their corporate governance not only on the grounds of transparent and effective communications with stakeholders as recipients, but also in terms of their involvement in defining the goals related to the triple bottom line. The fourth OECD corporate governance principle states that "The corporate governance framework [...] encourages active co-operation between corporations and stakeholders in creating wealth, jobs, and the sustainability of financially sound enterprises (OECD, 2014)".

Indeed, two key terms of this principle are "cooperation" and "creation". Stakeholders are not merely considered as recipients of the communication but rather as partners able to contribute to creating wealth, jobs, and sustainability.

\section{CSR and Italian Public Sector}

Scholarship and the experiences gained in the private sector have also significantly inspired the Italian public sector that since the 2000s has invested a great deal in communicating social responsibility with the aim of bringing the public sector closer to citizens.

A communication tool widely used by public administrations has been the social report. This tool constituted the outcome of a well-defined and managed innovation path for subsequent steps (Table 1).

Table 1 - The path towards the social budget

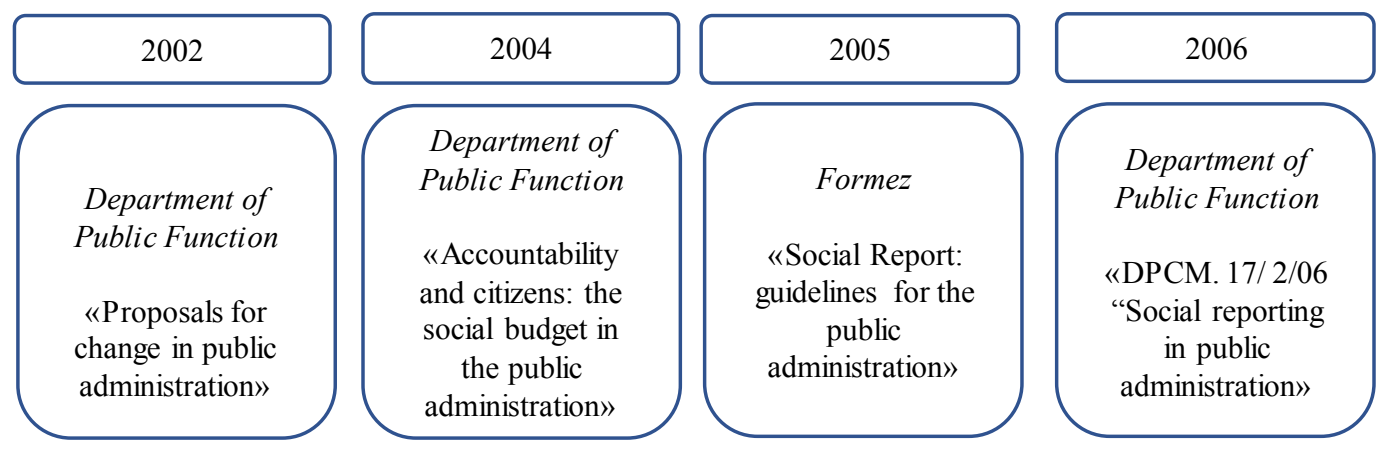

Edited by: University of Milano-Bicocca

ISSN: 1593-0319 
A careful analysis of social reports in the first years of the third millennium highlight:

- on the one hand, that municipalities and provinces once again were the most reactive organizations in transposing and introducing this tool;

- on the other hand, the methodologies used were often not the result of in-depth reflections or the comparison with other experiences.

In a word, the implementation of social responsibility communication tools social reports first and foremost - seems to have followed pathways marked more than anything by the need to respect tight deadlines for drafting the document (often "electoral" times) and the absence of sufficiently consolidated methodological references.

Within this framework, the "Social Report: a Territorial Public Administrations reporting tool" was introduced and promoted by the Department of Public Administration. This project has the task of defining, at the national level, guidelines for drafting social reports aimed at the entities issuing this complex document (D.P.C.M., 17 february 2006).

In particular, the guidelines have the following objectives:

- guide the social report practices of public administrations through the identification of general principles that - while respecting the autonomy of the single bodies - help them in the adoption of the instrument;

- define the meaning, purposes, basic contents, the process of implementation, and the criteria for using the social report;

- contribute to the adoption of a shared and comparable method of social accountability by the various public administrations;

- spread the culture of administrative transparency and encourage the construction of a permanent dialogue between institutions and citizens.

As noted, beyond the intent to provide technical support is the important purpose of promoting a culture of social responsibility based on the need to report the value created by the administrative actions in relation to the resources directly or indirectly requested of the community of reference.

The guidelines apply to all public administrations, despite their different legal and institutional forms, organizational structures, and contexts. Clearly, since these are "general principles", each administration then has to adapt them to the specific context and use the social report in a manner consistent with the institutional aims and the information needs of its stakeholders.

Starting from these purposes, the guideline document is structured as follows:

- purpose and characteristics of the social report in which the public administration's aims and main inspiring elements are defined;

- contents of the social report, clarifying the information that the social report must contain;

- implementation of the social report, indicating the methods for drafting the social report and structurally inserting it into the individual institution's reporting system.

After the adoption of these guidelines, the Observatory for Finance and Accounting of Local Authorities of the Ministry of the Interior intended to define a similar document aimed specifically at Italian municipalities and provinces. In fact, on 7 June 2017, the Ministerial Commission approved the "Guidelines for Social 
Reporting in Local Authorities". The purposes of this document are summarized as follows:

- investigate how the institution can meet the accountability needs deriving from exercising its role;

- render the social reporting methods and processes uniform, contributing to monitoring and the comparability of results;

- promote the participation of stakeholders in the definition of programs and in the evaluation of the administration's results;

- support the asseveration of social reports.

Interesting to note is the transposition of the social report definition already provided in Prime Ministerial Decree 17/02/06: "The social report is the outcome of a process by which the administration accounts for the choices, activities, results, and the use of resources in a given period, so as to allow citizens and various stakeholders to know and formulate their own judgment on how the administration interprets and realizes its institutional mission and its mandate" to:

- guarantee continuity with the institutional path initiated by the Department of Public Administration for the public sector as a whole;

- constitute a coherent reference, but "dedicated" to the reality of local authorities.

On the content side, the document, after having framed the social report within the more general reporting system, provides specific indications concerning:

- the structure and content of the social report. To this end, a basic structure is outlined divided into macro areas of intervention, considered more functional to represent information to support dialogue with the various stakeholders. Attention is also paid to those elements of the document (such as financial, economic, and equity resources) linked with the reporting system in a relevant manner.

- reporting process. In this context, in addition to internal involvement and external stakeholders, the administration's formal commitment, from the start of the reporting process, is particularly important as a prerequisite for guaranteeing continuity. Another significant element, in line with the most advanced international experiences, is the explicit provision of social report asseveration, seen as a guarantee for the development of a credible and non-self-referential reporting process.

Following this precise classification provided by the legislator, those years saw a significant development in terms of the quality and quantity of social reporting procedures and the related instruments that support it.

In a certain sense, it seemed that Italian public administrations were moving towards incorporating the social report within the traditional reporting tools required by accounting standards (such as management reports).

A study carried out by the Department of Public Administration clarified that the social report informs and feeds back on the institution's entire planning and control system, so as to make it more social in its essence and development mode. As such, the social report is not just an instrument for external communication, but almost a disclosure tool for citizens on what the institution produces and knows through other reporting tools; in fact, based on the experience gained in recent years, it can also represent an important opportunity to rethink and synthesise the tools already available internally, helping the administration to better orientate and focus its choices and internal control and evaluation systems. 
The social accountability perspective conditions not only the ex-post reading of the results, but also the way in which the choices were formulated and the preventive actions decided upon, assessing their actual and expected impact. It must therefore be an integral part of the overall system of the formulation of choices, definition of objectives, planning of actions, monitoring and evaluating the entity's results.

However, unlike the private sector, where corporate social responsibility has developed and rooted as other management branches, the Italian public sector saw a sudden turnaround, which began at the end of the first decade of the century concomitant with the development of financial policies characterized by linear cuts in public spending.

In fact, the lack of resources has progressively weakened the most innovative transversal functions, starting from the inducements of the local self-government reform, public employment, accounting, the communication methods and relations with citizens.

Programming, strategic and management control, organization and communication were the first corporate functions affected by the spending constraints. This choice, on the one hand, was justified by two underlying and common motivations:

- the "traditional" support functions (accounting, general affairs, personnel, etc.), besides having "equal dignity" compared to the innovative functions, represent the "vital minimum" for the existence of an organization;

- final services to citizen are a priority for the institution. Transversal functions are not visible to citizens and therefore their proper functioning does not "pay" at the level of electoral consensus. A cut in contributions, school meal coupons, or in whatever the municipality has always delivered is immediately perceptible, generating ill-feeling, and contrasting with the need for short-term "institutional returns" that have always characterized policy.

However, in recent years, this behaviour has undermined the innovation possibilities of Italian local authorities.

In fact, in a short time, we have witnessed a situation in which on the one hand:

- institutions have been called on to manage ever-increasing levels of strategic and organizational complexity, operating progressively in a "network" logic, transforming themselves from "direct" service providers to "regulators" of the best forms of managing these;

- the logic of extended governance requires inter-institutional coordination and a constant orientation towards stakeholder relations;

- accountability is a priority for citizens, users, taxpayers, and local partners, particularly due to the ever-decreasing resources available.

On the other hand:

- intensifying electoral rhythms have led to the need to obtain immediate and visible results, concentrating spending on services for citizens;

- the continuous cuts have reduced to a minimum the staff that can develop new approaches and techniques to govern the complexity, including reporting and social communication tools.

This situation has led, at a time when the importance of activating inclusive pathways has been made evident by numerous parties (see, by way of an example, 
the very current topic of smart cities), to reducing social accountability and the tools dedicated to this to an absolutely marginal role in the Italian landscape of management techniques, leaving the role of overseeing these issues to very few "innovators".

\section{Bibliography}

Arrigo, E., (2012). Alliances, Open Innovation and Outside-In Management, Symphonya. Emerging Issues in Management (symphonya.unimib.it), (2), 53-65.

http://dx.doi.org/10.4468/2012.2.05arrigo

Brondoni, S.M., Mosca F. (2017). Ouverture de "Integrated Corporate Social Responsibility", Symphonya. Emerging Issues in Management (symphonya.unimib.it), (1), 8-24.

http://dx.doi.org/10.4468/2017.1.01ouverture

Brondoni, S.M., (2003). Network Culture, Performance and Corporate Responsibility, Symphonya. Emerging Issues in Management (symphonya.unimib.it), (1), 8-24. http://dx.doi.org/10.4468/2003.1.02brondoni

Cantino, V., Cortese D., (2017). Integrated Report System in Italian Law, Symphonya. Emerging Issues in Management (symphonya.unimib.it), (1), 83-94.

http://dx.doi.org/10.4468/2017.1.07cantino.cortese

D.P.C.M., 17 february 2006. Department of Public Function - Presidency of the Council of Ministers.

Freeman, R.E., Dmytriyev S., (2017). Corporate Social Responsibility and Stakeholder Theory: Learning From Each Other, Symphonya. Emerging Issues in Management (symphonya.unimib.it), (1), 7-15. http://dx.doi.org/10.4468/2017.1.02freeman.dmytriyev

Freeman, R.E., Wicks, A.C., Parmar, B., (2004). Stakeholder Theory and "The Corporate Objective Revisited", in Organization Science, 15(3), 364-369.

https://doi.org/10.1287/orsc.1040.0066

Hawken, A., Lovins, L., Hunter Lovins, L. (1999). Natural Capitalism, Creating the next Industrial Revolution. New York, Little, Brown and Company.

Lambin, J.J., (2014). Rethinking the Market Economy, Symphonya. Emerging Issues in Management (symphonya.unimib.it), (2), 4-15.

http://dx.doi.org/10.4468/2014.2.02lambin

Mosca, F., Civera C., (2017). The Evolution of CSR: An Integrated Approach, Symphonya. Emerging Issues in Management (symphonya.unimib.it), (1), 16-35.

http://dx.doi.org/10.4468/2017.1.03mosca.civera

OECD, (2014). Principles of Corporate Governance.

Pollina C., (2017). Corruption, Performance and Participation, Symphonya. Emerging Issues in Management (symphonya.unimib.it), (2), 47-56.

http://dx.doi.org/10.4468/2017.2.05pollina

Porter, M.E., Kramer, M.R. (2007), Strategia e società. Il punto di incontro tra il vantaggio competitivo e la Corporate Social Responsibility. Harvard Business Review Italia, 1-2.

Ricotti, P., (2003). Corporate Responsibility and Sustainable Development, Symphonya. Emerging Issues in Management (symphonya.unimib.it), (1), 84-98.

http://dx.doi.org/10.4468/2003.1.08ricotti

Salvioni, D.M., Gennari, F., (2017). CSR, Sustainable Value Creation and Shareholder Relations, Symphonya. Emerging Issues in Management (symphonya.unimib.it), (1), 36-49. 
(C) SYMPHONYA Emerging Issues in Management, n. 1, 2018

symphonya.unimib.it

http://dx.doi.org/10.4468/2017.1.04salvioni.gennari

Salvioni, D.M., Bosetti, L., (2014). Sustainable Development and Corporate Communication in Global Markets, Symphonya. Emerging Issues in Management (symphonya.unimib.it), (1), 32-51.

http://dx.doi.org/10.4468/2014.1.03salvioni.bosetti

Salvioni, D.M., (2003). Corporate Governance and Global Responsibility, Symphonya. Emerging Issues in Management (symphonya.unimib.it), (1), 44-54.

http://dx.doi.org/10.4468/2003.1.05salvioni

The Economist Supplement, (19 january 2008). Corporate Social Responsibility.

The Economist Supplement, (22 january 2005). The Good Company - A Survey of Corporate Social Responsibility. 